\title{
The Role of Art-Integrated Input: Implementing Arts to Maximise English Proficiency among Saudi English-Major Undergraduates
}

\author{
Rashidah Albaqami \\ Foreign Language Department, Taif University, Taif, KSA \\ Email:r.mohamad@tu.edu.sa
}

How to cite this paper: Albaqami, R. (2020). The Role of Art-Integrated Input: Implementing Arts to Maximise English Proficiency among Saudi English-Major Undergraduates. Open Journal of Modern Linguistics, 10, 260-276.

https://doi.org/10.4236/ojml.2020.104015

Received: June 15, 2020

Accepted: August 1, 2020

Published: August 4, 2020

Copyright $\odot 2020$ by author(s) and Scientific Research Publishing Inc. This work is licensed under the Creative Commons Attribution International License (CC BY 4.0).

http://creativecommons.org/licenses/by/4.0/

\begin{abstract}
Factors that affect foreign/second language (L2) acquisition include internal factors related to the learners such as motivation and personality-related style preferences as well as external factors related to the learning process such as the amount and quality of input and more interestingly how the latter factors can enhance the former. This paper examines the role of input quality (instructional) during the course of L2 development by integrating arts to facilitate L2 development and boost the learners' motivation by engaging them with masterpieces from classical art as a stimulus. A total number of 30 Arabic learners of English as a foreign language took part in this quasi-experimental study. The experimental group $(\mathrm{n}=20)$ was enrolled in a teaching setting rich with input full of triggers by integrating arts including dramatization and art expedition (e.g. painting, photographing, and sculpting), whereas, the control group $(\mathrm{n}=10)$ was enrolled in a traditional teaching setting. Three instruments were final examinations administered at the end of each semester. Independent-samples t-test was run to identify whether any significant difference existed in L2 proficiency of the control and experimental groups. The findings suggest that L2 learners who were exposed to the instructional settings highly enriched with robust and art-integrated input significantly performed better in L2 proficiency. This suggests that art-integrated input significantly enhanced proficiency of Saudi EFL learners.
\end{abstract}

\section{Keywords}

Input Quality, Poverty of the Stimulus, Art-Integrated Input, Content-Based Instruction, English-Major Undergraduates 


\section{Introduction}

Saudi learners of English as a foreign language (EFL) have been reported as having poor proficiency (Alrahaili, 2013; Alrashidi \& Phan, 2015; among others). This low proficiency can be attributed to a wide range of factors, including input. The role of input in improving language proficiency has been widely acknowledged. According to different approaches, learners need to have access to quality and quantity input to successfully master the target language. Ellis (2014: p. 38) claims that "If learners do not receive exposure to the target language, they cannot acquire it." This paper sheds light on the role of input quality in enhancing EFL achievement in the Saudi context.

\section{Statement of the Problem}

This study is an attempt to address the question that arises as to what extent interlanguage grammar of the $\mathrm{L} 2$ learners can be refined with providing fine-grained linguistic experience (i.e. exposure to sufficient and enriched input such as art-integration). Much evidence suggests that L2 development is triggered by subtle input that L2 learners are exposed to. Language development can be examined from all sorts of perspectives. In this study, the issue is approached from generative perspectives to L2 development. The present study endeavors to determine what is the effect of input quality on L2 development in EFL context of Arabic speaking country. And, more interestingly, the study attempts to identify which form of instructional "usage-based" input (traditional vs. art-integrated) is more effective in L2 development. This study examines the effects of L2 input within the instructional L2 learning settings. One needs to consider the actual role of the amount and quality of the instructional L2 input that the L2 learners are exposed to. The difference between the types of instructional input found in the L2 development contexts; i.e. the traditional where learners are exposed to limited unplanned usually poor input vs. the art-integrated where learners are exposed to highly robust ample input. This experiment contributes to identify the kind of L2 knowledge that L2 learners might build based on the forms of input offered in each context. Are the L2 learners in an instructional-input-oriented environment offered very rich L2 input? Put differently, this paper sheds lights on the role of input in constructing conceptual representations, as observed by the learners' internal mechanisms during the course of L2 development, eventually resulting in a "change in an individual's internal mental state" as Doughty and Long (2003: p. 4) have stated.

\section{Literature Review}

There are several factors (i.e. internal and external) which have an impact on second language (L2) development. It is widely accepted that for L2 development to occur, there must be two necessary conditions: 1) L2 input that the learners are exposed to and 2) a set of internal mechanism to explain how L2 samples are processed (Ellis, 1995). In language development, input is defined as 
the data which the learners are exposed to. It is now widely acknowledged that input offered to the L2 learners during the learning process plays a very essential role in language development, and the amount and quality of the input affect the L2 development directly. The role of input amount and quality has been a highly debatable matter in the realm of L2 development.

The internal factors comprise the conceptual disposition of learners and the capacity to tackle communication. The external factors include the circumstances to which the learners are exposed and they might embrace the frequency of the exposure accessible for the L2 learners (i.e. amount of the samples of the L2, namely the input) and the quality of those samples.

Having said that the input plays an important role in L2 development, it has recently received substantial consideration by the researcher in the field. In generative approached to L2 development, there is a call for further advanced systematic study of input in L2 development (Carroll, 2001; Gregg, 2001). There is a large volume of published studies which have focused on the role of positive or negative input in mastering L2 (Zhang, 2009). Inagaki (2001) proposes that L2 evidence should be accessible and robust (i.e. recurrent and unambiguous) for better L2 development. Krashen and Terrell (1983) argue that if input is delivered naturally over wide-ranging themes for interaction purposes, the input would typically comprise the necessary linguistic data. Hence, acquisition is considered as an unconscious natural process that occurs owing to meaningful exposure that takes place naturally and is used for meaningful interaction purposes. This natural and unconscious process of acquisition is different from the conscious process of language learning, which takes place when instructional input is offered consistently.

Ellis (1994, 2008a, 2008b) points out that various theories of L2 development differently assign importance to the role of input in language development but they all acknowledge the prerequisite for input in general. In several approaches to L2 development, input is regarded as a crucial factor whereas in others it has been assigned a minor role. That is, those theories differently conceptualize how input is treated by learners bearing in mind the quality of input, i.e. natural or instructional (Doughty \& Long, 2003).

Therefore, input is essential and there is no approach to L2 development that does not acknowledge its importance. According to Schwartz (1993), the input supports an innate system to support its development. However, input alone cannot assist L2 development. It will not efficiently function in L2 development till it gets engaged in interaction. Different theories of L2 development have highlighted the importance of the quality of the input that the learners are exposed to. Experimental evidence is provided by Hassanzade and Narafshan (2016), who conducted a study to examine the impact of input quality (i.e. natural vs. instructional). They conclude that both natural and instructional input promoted L2 knowledge. However, they support the superiority of instructional input over the natural input in promoting L2 development. 
Some suggest that formal instruction supports L2 development, whereas others claim that informal conditions have a greater impact. To have a better understanding to this issue, Krashen (1985) proposes the Input Hypothesis in which he claims that language classes are more effective when they allow for more primary basis of comprehensible input. The Input Hypothesis hence is the heart to all of acquisition, i.e. L2 development relays on comprehensible input. In instructional contexts, learners must receive comprehensible input by offering them with highly sophisticated linguistic materials. Nevertheless, his hypothesis has been challenged by evidence found in several studies demonstrating that comprehensible input alone is inadequate for L2 development (e.g. Harley \& Swain, 1984). According to several scholars (e.g. Sharwood Smith, 1986; Crookes, 1991), processing comprehension is unlike processing production and the aptitude to comprehend meaning expressed by structures varies from the aptitude to use linguistic system to deliver meanings. Learners generate output in interaction once input is negotiated. They absorb parts of comprehensible input and select target-like forms to deliver meanings. This process allows the learners to linguistically internalize what they have experienced.

This brings the question of whether or not input involves an equal amount of intake (Zhang, 2009). Corder (1967) distinguishes between input and intake. He describes input as what the learner has access to, while intake denotes what the learner truly internalizes. This distinction is explained by good deal of evidence in L2 learning practices. It is claimed that L2 development will not take place even if with input at the target amount and quality but without being processed by the learners.

Numerous theories have attempted to account for the issue of input including: innatist, behaviorist and interactionist. Each one holds a different perspective in accounting for L2 development. First, the innatists highlight the importance of the learner's internal mechanism. They argue that the human brain is principally prepared to master language and all that is required is minor exposure to input in order to activate the relevant development (Ellis, 1997). On the contrary, the behaviourists view language development as environmentally established and externally governed by the kind of stimuli the learners have access to and the reinforcement they obtain afterwards. On the other hand, the interactionists recognize the importance of equally both external factors and internal language processing, highlighting the mutual involvement of environment as well as the learners' internal mechanism in settings where interaction can take place.

Within the generative framework to language development, Chomsky (1981) proposes the theory of Principles and Parameters. The generative approach to language development assumes a biological device dedicated in language development, explicitly Universal Grammar (UG). The biological and innate device that is in charge of language development does not eliminate the role of the environment. The language organ counts on the input available in the environment in the same manner that children need to be nurtured in order to physi- 
cally grow. This does not mean that language will advance independently of the stimulus. This explains the fact that during the process of L1 development, children rapidly construct countless structures in a limited amount of time. This process is activated by the constructions exist in the L1 input, that the child is exposed to in the environment. Marcelino (2018: p. 78) claims that "the input in L1 is disorganized, unplanned, fragmented and based on positive evidence". From an acquisitional standpoint, children at certain age (approximately at the age of four) will attain the grammar of their L1, due to their innate language constructing capacity. This must be achieved in the existence of robust input of their L1. Similarly, rich exposure to robust ample L2 input should, in theory, generate similar outcomes, even if it is not consistently.

Put differently, according to Chomsky $(1981,1986)$, during the process of L1 development, it is anticipated that children develop their L1 grammar by being offered with robust input, hence the input plays an essential role. This input comprises the Primary Linguistic Data (PLD) from which the child can have access to the essential information to develop his/her L1 grammar. That is, input in L1 development seems to be rationally guaranteed and inclusive, thus that it will comprise all the essential data for the child to obtain all the evidence that will direct building his/her L1. The child only has to rely on his/her natural innate aptitude to master the L1. Logically speaking, this postulation brings the question to what extent the same fact is accurate in relation to L2 development.

In the generative perspective of L2 development, a large and growing body of literature has investigated the enquiry of whether the UG innate device has a role in L2 development and does it bear any comparison to L1 development. A large volume of published studies lends support to the argument that UG remains fully accessible for L2 development (e.g. Dekydtspotter et al., 2001; Slabakova, 2008; Schwartz \& Sprouse, 1996, 2013; White, 1985, 1989, 1990, 2003). Several studies state that L2 development is commonly inspired by L1 development studies in relation to the role of UG mechanisms. Though, some kind of parameter resitting is needed with respect to L2 development.

As far as L2 development is concerned, the process of L2 development is triggered by the representations in the L2 input which is available for the L2 environment. The input in L2 seems more organized, planned, integrated and can be based on both negative and positive evidence. Positive evidence is the input in is described as the form of acceptable structures, as against Negative evidence, which comprises examples of what is unacceptable to say, namely corrective feedback. The importance of providing the learners in the L2 context with optimal and robust input is as a means of maximizing the chances to master and develop the L2. Similar to L1 development, the input, available in the environment, comprises the PLD that is needed to offer the crucial information (i.e. triggers) required to set the relative parameters to build the target knowledge. In L2 development, it is not evident that by mastering one representation in L2, all 
the other representation will become immediately accessible in the learner's interlanguage, just like the case in L1 development. Moreover, the L2 input is less likely to be as rich and robust as it is in L1, especially in classroom-based settings as Marcelino (2018) points out.

Bearing in mind that several factors may have an impact on the amount and quality of the explicit L2 input, influencing the L2 development is a major one in this regard. Extensive research has shown that L2 learners are able to master a language by being exposed to robust input. Nevertheless, one should consider that in Arabic-English context, the input that the L2 learners are exposed to might not be robust enough because of several factors including (1) amount of L2 exposure (approximately 2 hours or 4 hours per day); 2) the nature of interaction (what is the aim of mastering the L2? reading plays or for communication purposes) and 3) lack of the crucial PLD that L2 learners must have to construct the L2 properties. It is a common belief that by simply using an L2 in any context will offer the L2 learners with the essential linguistic data. Nevertheless, this is unlikely to be adequate to assure that they can use their linguistic aptitudes to the best effect. However, this drawback can be avoided by creating a solid program for L2 development that embraces advanced pedagogical blueprint. This program should comprise input that is ample, robust, frequent, diverse, wide ranging, relevant and meaningful, and unambiguous. That is, it must comprise sufficient information, for example, that will support the learner to develop the relevant linguistic property. However, unlike the L1 input, the L2 input is unlikely to be available in the L2 environment at all times.

So far, one might ask why L2 instructional input is important. Initially, "there is a general consensus in the literature that instruction may speed up the acquisition of some surface aspects of language." as Smith and Vanpatten (2014: p. 143) claim. Secondly, Marcelino (2018: p. 86) accounts for the importance of input and claims that

"Independently of how the language is presented, it is perceived by the human mind and its internal mechanisms as data to be assigned mental representations. The overrated role of the progressively organized L2 input in this perspective is reduced to a minimum. All of the organized, modified, progressive, and rule-based L2 instructional approaches to language teaching are treated as input by the brain. The rest remains as problem-solving tasks".

The L2 learners attend the target language in instructional settings, but there is no planned emphasis on language development or the sort of input that L2 learners are exposed to. Input, hence, takes the form of unplanned practice of language made available in instructional settings. This approach relies on the invalid assumption that in the Arabic-English context, targeting whatever L2 input to the L2 learners would serve for L2 development. In the Arabic-English context, the L2 learners can merely master the L2 by practicing it. Besides, it will 
not offer the required PLD to support them put their language constructing ability to the best practice. The learners are likely to use constructions that hold a similarity to those of their L1 but with L2 constructions. They are linking the assumed "L2 configurations" to the L1 parameters. The outcome would be, unavoidably, what is called interlanguage, which definitely would need further remedial effort. The term "interlanguage grammar" was coined by different linguists (cf., Adjemian, 1976; Corder, 1967; Selinker, 1972). In the Arabic-English context, one cannot merely rely on the normal adjusted L2 instructional input to advance L2 development. They need to do more work. In Saudi Arabia, classes largely vary in the amount of L2 instruction and L2 input that learners are structurally exposed to. This structured exposure is based on the L2 parameters (i.e. developing input with the needed parameter-trigging linguistic configurations).

Proponents of the UG approach acknowledge that some properties of language are "too abstract, subtle, and complex to be acquired in the absence of innate and specifically linguistic constraints on grammar" (White, 2003: p. 20). Put differently, input alone is not sufficient. Nonetheless, learners master those complex properties of language, as mirrored by their spontaneous judgments and target like production. Hence, learners' linguistic proficiency ultimately exceeds the samples accessible in the input; alternatively stated, the input under-determines the language properties. This fact, is known as the logical problem of language development or Poverty of the Stimulus (POS) (Chomsky, 1965). From the nativist-based viewpoint, the POS refers to two different conditions: 1) conditions in which the input appears to be vague, possibly resulting in the learners to overgeneralize inappropriately, and 2) conditions in which the input is deficient found in unplanned poor linguistic settings, namely, it merely does not deliver sufficient evidence of a precise property.

Sophisticated exposure to L2 can occur by, for instance, implementing visual arts which can be used to teach not only language but also culture as well. This method is called "two for one" or Content Based Instruction (CBI) which supports learners to treat the language as a mean, rather than a goal (Shier, 1990; Lightbown \& Spada, 2006). From a usage-based perspective, several studies suggest that teaching forms as well as contents at the same time enlarges authenticity of the language by offering natural settings where learners practice the language as native speakers and have more chances to practice their linguistic skills (Rodgers, 2011; Cross, 2012). Nevertheless, Hoare and Kong (2008) claim that this beneficial method is not commonly used in classrooms due to the fact that instructors typically pay more attention to linguistic skills at the cost of content. Long (2000) suggests alternative justification for why instructors are unwilling to make use of the CBI approach as it requires more systematic and methodological preparation for teaching plans that are not typically incorporated in the module materials. Therefore, instructors stick to the same pre-designed arrangement of grammatical representations and unconnected cultural themes which make the 
learners' linguistic familiarity limited and lessen their "language authenticity" as Cross (2012) suggests.

A considerable amount of literature has been published on the role of art-integration in language teaching and learning (e.g. Moore et al., 1994; Ghandbari, 2015). Evidence from these studies suggests that art-integration significantly advances L2 development and greatly expands L2 knowledge. LaJevic (2013: p. 2) defines art-integration as "a dynamic process of merging art with (an)other discipline(s) in an attempt to open up a space of inclusiveness in teaching, learning and experience. [it is] an arts focus approach to learning and teaching". The arts may include, for instance, painting, photographing, sculpting, acting, and singing which may facilitate mastering the L2 across many different areas.

\section{Research Methodology}

\subsection{Research Objectives}

This study aims to identify the following research objectives:

1) The role of art-integrated input in enhancing English language proficiency of Saudi EFL learners.

2) The difference in the level of English language proficiency of Saudi EFL learners exposed to art-integrated as compared to Saudi EFL learners exposed to traditional input.

3) Is there any statistically significant difference in English language proficiency of Saudi EFL learners exposed to art-integrated input as compared to Saudi EFL learners exposed to traditional input?

\subsection{Research Questions}

This study attempts to answer the following questions:

Q1: What is the role of art-integrated input in enhancing English language proficiency of Saudi EFL learners?

Q2: Do Saudi EFL learners exposed to art-integrated input outperform Saudi EFL learners exposed to traditional input in their English language proficiency?

Q3: Is there any statistically significant difference in English language proficiency of Saudi EFL learners exposed to art-integrated input as compared to Saudi EFL learners exposed to traditional input?

\subsection{Research Hypotheses}

\subsubsection{Null Hypothesis}

The study in hand aims to test the following null hypothesis:

$\mathrm{H}_{0}$ : There is no any statistically significant difference in English language proficiency of Saudi EFL learners exposed to art-integrated input as compared to Saudi EFL learners exposed to traditional input.

\subsubsection{Alternative Hypothesis}

The study has the following alternative hypothesis:

$\mathrm{H}$ : There exists statistically significant difference in English language profi- 
ciency of Saudi EFL learners exposed to art-integrated input as compared to Saudi EFL learners exposed to traditional input.

\subsection{Research Design}

The study in hand is a quasi-experimental which aims to identify the role of art-integrated input in enhancing English language proficiency as determined by final examination tests. A total of 30 female students from the Foreign Languages Department at Taif University took apart in the experiment. The experimental group consisted of 20 students whereas the control group was 10. The experimental group in the L2 context was offered optimal art-integrated input with the aim to enhance their English language proficiency. They were continuously exposed to art-integrated input inside and outside classroom context. The experimental group was offered plenty of time for practising English. They were adequately exposed to a wide range of art-integrated input in L2 in spoken and written forms on a daily basis. The control group, on the other hand, received the regular amount of input available in the L2 traditional context. The study was carried out through three semesters. Each semester was of three months duration. All participants were randomly assigned into two classes (traditional vs. art-integrated) in the beginning of the academic year. Both classes were taught by the same instructor.

\subsection{The Participants}

The researcher has selected the English-major students studying at foreign languages department of Taif university, Saudi Arabia because the researcher has long interaction with them as their teacher and they were most appropriate to conduct this quasi-experiment as they lack English language proficiency to carry out their studies with ease as reported by Javid et al. (2012) who have investigated English-major undergraduates of same university. Generally speaking, the students at the department usually find it difficult to accomplish their tasks when it comes to the literary texts in L2. Therefore, it seems important to increase their motivation through the exact same challenging area of literature to enhance their English language proficiency so that they may be able to handle their literary courses efficiently. It is noticed that there are three major areas of difficulty faced by the students: 1) the barrier of language itself (i.e. the L2), 2) the intercultural varieties, and 3) the matters of the individual literary taste (i.e. value appreciation) of each student. The research used the strategies of involving the students more in determining their own levels of appreciation of their tasks through role play including dramatization of the literary texts as well as an art exhibition project.

\section{Experimentation}

\subsection{Dramatization}

The study examined the participants of this study on three literature related 
courses which were " $18^{\text {th }}$ Century Drama", " $19^{\text {th }}$ Century Drama”, and "Modern British Drama". The participants were immersed with the environment full of meaningful and comprehensible messages in the L2. An example of such an immersion was dramatization of the plays in the L2. A total of 20 students performed different scenes from Pygmalion and Arms and the Men by George Bernard Shaw $(1999,2006)$. The participants regularly worked with the instructor in class preparing for the final performance once a week for 8 weeks. This preparation required spending extra hours at home where the participants continuously searched, read, listened and practiced for the final performance.

\subsection{Art Exhibition}

The next step was an art exhibition project for the participants of this experimental study. Art exhibition was put together initially to stimulate the participants' creativity, critical thinking and innovation through taking an inside classroom experience into an outside one to achieve real performance through direct and authentic situations. The participants were allowed to connect the targeted language immediately to its natural culture through the exploitation of art: painting, photography, and sculpting. Their journey to explore English literature through art, aided by the various characteristics and versatile features of different literary centuries (i.e. the targeted centuries were $16^{\text {th }}, 17^{\text {th }}$, and $18^{\text {th }}$ respectively). The participants selected a work of art from $16^{\text {th }}$ to $18^{\text {th }}$ century and a literary piece that complemented the selected work. Then, each one delivered assimilation painting, photographing, or sculpting and a description of the work along with an explanation for the complementary literary piece she had chosen. Art exhibition was an idea to reflect a glimpse of English literature which is considered an essential component for the study of English Language. Every single painting, photograph, or sculpture was a portrait of a work of literature that represented a specific period of the Renaissance, Reason, and Restoration centuries. Examples of the works produced by the participants in the art exhibition are shown in Figure 1.
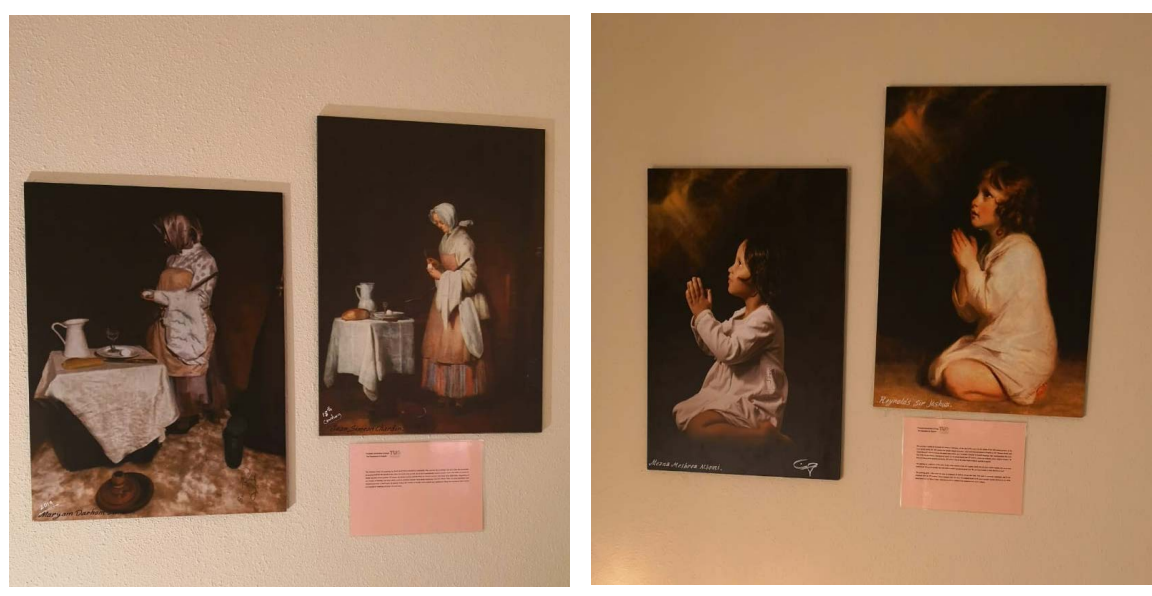

Figure 1. Examples of the works produced by the learners in the art exhibition. 
Afterwards, the performance of the participants across the three courses was examined (i.e. their scores on the final exams). The first test was a pre-test prior to any refined input the experimental group was exposed to. Whereas, the second test was a post-test followed the first amount of the refined input "implementing arts" (i.e. dramatization). The third test was a post-test followed the second amount of the refined input "implementing arts" (i.e. art exhibition). Next, the instructor and the participants were interviewed to account for any progress noticed.

\section{Results and Findings}

The study intended to investigate the impact of art-integrated input on Enhancing English as s Foreign Language Proficiency among Saudi English-major Undergraduates. The study attempted to answer the following main research question: What is the role of art-integrated input in enhancing English language proficiency of Saudi EFL learners? An independent-samples t-test was conducted to compare the performance of the two groups in traditional and art-integrated instructional conditions in pre-test and post-test. There was a significant difference in the scores for art-integrated input $(\mathrm{M}=86.90, \mathrm{SD}=8.22)$ and traditional input $(\mathrm{M}=71.90, \mathrm{SD}=11.17)$ conditions; $\mathrm{t}(28)=4.18, p=0.000$. These results suggest that the type of input bear statistically significant effect on the participants' performance. Specifically, the results suggest that when L2 learners are exposed to art-integrated input that is ample and sophisticated, their performance significantly increase as Table 1 shows.

The most outstanding result to emerge from the data is that there is a correlation between the input quality and L2 proficiency. The findings suggest the superiority of the highly refined art-integrated input over traditional input in supporting L2 proficiency. As shown in Figure 2, the experimental group which was exposed to art-integrated input outperformed the control group being exposed to the traditional input. That is, art-integrated input was found to be significantly more effective than traditional input. As expected, the performance of the

Table 1. Descriptive and independent samples t-test.

\begin{tabular}{lccccccc}
\hline \multicolumn{2}{c}{ Groups } & $\mathrm{n}$ & Mean & $\begin{array}{c}\text { Std. } \\
\text { Deviation }\end{array}$ & $\mathrm{t}$ & $\mathrm{df}$ & $\begin{array}{c}\text { Sig. } \\
(2 \text {-tailed })\end{array}$ \\
\hline \multirow{2}{*}{ Test 1} & Experimental & 20 & 73.40 & 11.72 & 0.84 & 28 & 0.409 \\
& Control & 10 & 69.70 & 10.70 & 0.87 & 19.68 & \\
& Experimental & 20 & 82.00 & 9.36 & 3.37 & 28 & 0.002 \\
Test 2 & Control & 10 & 69.90 & 9.12 & 3.40 & 18.53 & \\
& Experimental & 20 & 86.90 & 8.22 & 4.18 & 28 & 0.000 \\
Test 3 & Control & 10 & 71.90 & 11.17 & 3.77 & 14.05 & \\
\hline
\end{tabular}

${ }^{\star}$ The mean difference is significant at the 0.05 level. 


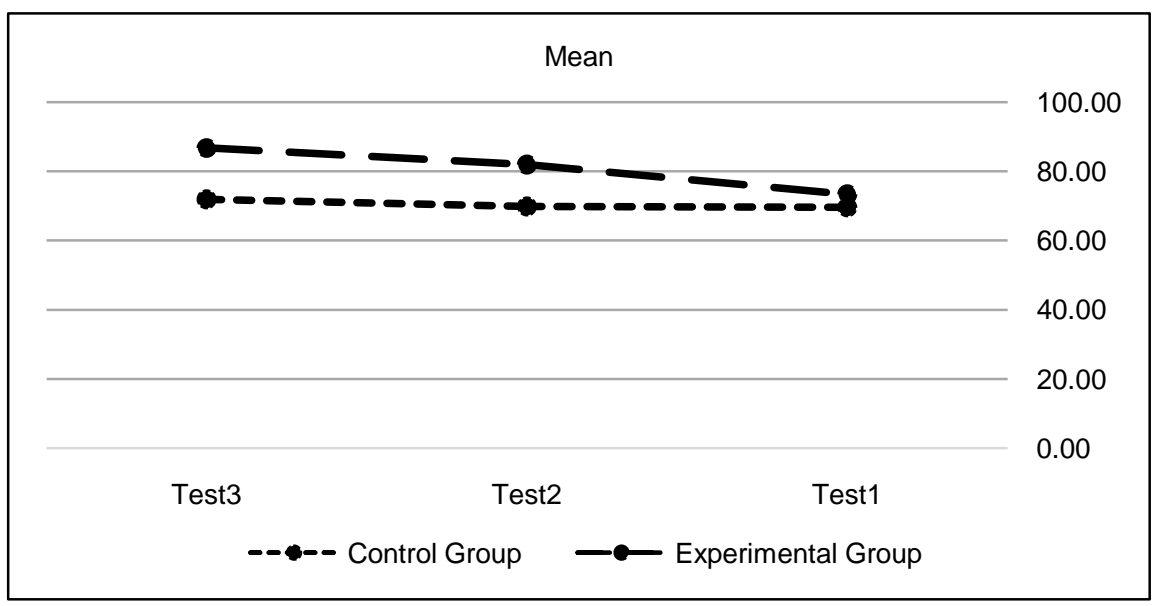

Figure 2. The performance of the two groups across the three tests. The scale shows percentage of the target responses out of $100 \%$.

control group remained the same. This suggests the prerequisite of art-integrated input that is highly sophisticated for fruitful L2 development. It follows the postulation that a better understanding of the amount and nature of L2 instructional input may result in better developments in L2 pedagogical practices and L2 development consequently.

The results suggest that ample and art-integrated input results in enhanced English as s foreign language proficiency among Saudi English-major undergraduates. The experimental group performed better at different levels. There exists statistically significant difference in English language proficiency of Saudi EFL learners exposed to art-integrated input as compared to Saudi EFL learners exposed to traditional input. Hence, the null hypothesis was rejected. This is evident by the fact that the L2 learners were more engaged and linguistically productive as compared to those at the traditional settings. Put differently, the input that experimental group was exposed to significantly boosts L2 development. This was achieved when learners faced a gap in their L2 knowledge. By noticing this gap, owing to the different and countless triggers available in the refined input, the learners were activated to adjust their interlanguage. This adjustment typically boosts mastering new facets of the L2 that have not been mastered yet. That is, the triggering input result in the restructuring of plenty properties of the interlanguage which in turn results in overcoming the POS at different linguistic levels. The more exposure to the triggering input, the more adjustments the learners are likely to attain, consequently the higher accuracy they are likely to achieve. Apparently, the findings suggest that the experimental group has overcome the POS problem and the impact of their L1 prior knowledge and successfully accommodated the L2 properties. Whereas, the traditional group has struggled due to the naturally-occurring input they have been exposed to which seems to lack the crucial triggers needed for the target adjustments to take place.

The instructor pointed out that the learners started to participate further and 
to form their own preferable about the assigned texts. They mastered the language by "doing" it, by active learning which seemed beneficial just like learning how to play a piano. No one can learn it without actually practising it; the more you practise, the better you perform. And the language barrier became to loosen up with a free joyful learning environment. She added that all the courses involved with drama became an aspect for interaction and negotiation among the students and instructor and among the students themselves and accordingly, they became more interested, motivated and active which helped to reform the individual literary preferences specially with the relative increased academic levels. Furthermore, the learners managed to overcome the obstacles of the inter-cultural barriers. The amount and quality of the input, the learners were exposed to, assisted their cognitive development and boosted L2 development. The amount of the efficient and effective input, that was full of triggers, worked as facilitator for L2 development. Finally, in the follow-up phase of the study, the participants were also asked about their experience. They reported that art-integration enabled them to deliver their thoughts efficaciously equally in both speaking and writing. It stimulated them to achieve higher accuracy and better fluency.

Generally speaking, by analysing the learners' writing samples, one can see that their writing skills have improved; their vocabulary selections have enlarged and their spelling and grammatical errors have lessened. That is, their L2 knowledge notably has been expanded. Not only in writings, the learners performed much better in speaking and interactions. This was evident during their performance on the theatre and in the art expedition as well. Interestingly, the learners' cognitive abilities, level of motivation and personal attitude towards the target language, and self-confidence have been remarkably boosted. This shows how robust is the fact that external factors (i.e. input) can effectively impact internal factors (e.g. motivation) and consequently result in better outcomes in L2 development.

\section{Conclusion and Implications}

As it has been stated, the L2 development is influenced by internal as well as external factors. Nevertheless, it is important to bear in mind that both factors must work in harmony as even a sufficient exposure to the L2 might not confirm L2 development if the learner is not willing. Offering suitable conditions that aim to facilitate the L2 development must be the purpose of language instruction. The present paper addresses the role of art-integrated input in L2 development exploiting the internal mechanisms that learners have from a generative perspective.

In terms of L2 development, evidence from this study shows that learners who are exposed to ample and highly sophisticated instructional input (i.e. art-integrated) are better L2 acquirers than the ones being exposed to traditional instructional input. The findings suggest that art-integrated input significantly promotes the 
L2 proficiency. The findings of this experimental study support the superiority of the art-integrated input over traditional input in expanding L2 development. More interestingly, the findings suggest that the establishment of the explicit input pointed to L2 learners appears fruitful, bearing in mind that it will be unconsciously allocated mental representations by the learners' mind, resulting in their interlanguage. This interlanguage corresponds to the precisely designed, gradually systematized explicit L2 input conveyed in highly instructed settings.

Taken together, these results provide important insights into language pedagogy. Robust and rich input should be offered in the L2 instructed learning settings to facilitate the conditions where the L2 learners put their best linguistic capacities to enhance their target language proficiency. To conclude, it is suggested that learners must be offered best possible fine-grained materials from which they can better shape and advance their L2 knowledge. Therefore, it seems extremely important for faculty members teaching Saudi English-major university undergraduates to incorporate art-integrated input in their teaching practices especially while teaching literary courses to enhance their motivation level and English language proficiency to cope up with their studies effectively.

\section{Acknowledgements}

The author gratefully thanks Dr. Ayat Abdulrahman for her participation in the experiment. Without her role as the instructor of the literary courses, the research would not have been completed. Heartfelt thanks are also extended to the other participants in the study.

\section{Conflicts of Interest}

The author declares no conflicts of interest regarding the publication of this paper.

\section{References}

Adjemian, C. (1976). On the Nature of Interlanguage Systems. Language Learning, 26, 297-320. https://doi.org/10.1111/j.1467-1770.1976.tb00279.x

Alrahaili, M. (2013). Predictors of L2 Attitudes and Motivational Intensity: A Cross-Sectional Study in the Saudi EFL context (PhD Thesis). Callaghan: The University of Newcastle.

Alrashidi, O., \& Phan, H. (2015). Education Context and English Teaching and Learning in the Kingdom of Saudi Arabia: An Overview. English Language Teaching, 8, 33-44. https://doi.org/10.5539/elt.v8n5p33

Carroll, S. E. (2001). Input and Evidence: The Raw Material of Second Language Acquisition. Amsterdam: John Benjamins. https://doi.org/10.1075/lald.25

Chomsky, N. (1965). Aspects of the Theory of Syntax. Cambridge: MIT Press. https://doi.org/10.21236/AD0616323

Chomsky, N. (1981). Lectures on Government and Binding. Dordrecht: Foris.

Chomsky, N. (1986). Knowledge of Language: Its Nature, Origin and Use. New York: Praeger.

Corder, S. P. (1967). The Significance of Learners' Errors. International Review of Ap- 
plied Linguistics in Language Teaching, 5, 161-170.

https://doi.org/10.1515/iral.1967.5.1-4.161

Crookes, G. (1991). Second Language Speech Production Research: A Methodologically Oriented Review. Studies in Second language Acquisition, 13, 113-132. https://doi.org/10.1017/S0272263100009918

Cross, R. (2012). Creative in Finding Creativity in the Curriculum: The CLIL Second Language Classroom. The Australian Association for Research in Education, 39, 431-445. https://doi.org/10.1007/s13384-012-0074-8

Dekydtspotter, L., Sprouse, R. A., \& Swanson, K. (2001). Reflexes of Mental Architecture in Second-Language Acquisition: The Interpretation of Discontinuous Combien Extractions in English-French Interlanguage. Language Acquisition, 9, 175-227. https://doi.org/10.1207/S15327817LA0903_1

Doughty, C. J., \& Long, M. H. (2003). A Handbook of Second Language Acquisition. Malden: Blackwell. https://doi.org/10.1002/9780470756492

Ellis, N. (1994). Implicit and Explicit Language Learning: An Overview. In: N. Ellis (Ed.), Implicit and Explicit Learning of Languages (pp. 1-31). London: Academic Press. https://doi.org/10.1075/sibil.48.01ell

Ellis, R. (1985). Understanding Second Language Acquisition. Oxford: OUP.

Ellis, R. (1995). Interpretation Tasks for Grammar Teaching. TESOL Quarterly, 29, 87-105. https://doi.org/10.2307/3587806

Ellis, R. (1997). Second Language Acquisition. Oxford: Oxford University Press.

Ellis, R. (2008a). Explicit Form-Focused Instruction and Second Language Acquisition. In B. Spolsky, \& F. Hult (Eds.), The Handbook of Educational Linguistics (pp. 437-455). Oxford: Blackwell. https://doi.org/10.1002/9780470694138.ch31

Ellis, R. (2008b). The Study of Second Language Acquisition. Oxford: Oxford University Press.

Ellis, R. (2014). Principles of Instructed Second Language Learning. In M. Celce-Murcia, D. Brinton, \& M. Snow (Eds.), Teaching English as a Second or Foreign Language (4th ed., pp. 31-45). Boston, MA: Cengage Learning.

Ghandbari, S. (2015). Learning across Disciplines: A Collective Case Study of Two University Programs That Integrate the Arts with STEM. International Journal of Education \& the Arts, 16.

Gregg, K. (2001). Learn Ability and Second Language Acquisition Theory. In P. Robinson (Ed.), Cognition and Second Language Instruction (pp. 152-180). Cambridge: Cambridge University Press. https://doi.org/10.1017/CBO9781139524780.008

Harley, B., \& Swain, M. (1984). The Interlangage of Immersion Students and Its Implications for the Second Language Teaching. In A. Davies, C. Criper, \& A. Howatt (Eds.), Interlanguage (pp. 291-311). Edinburgh: Edinburgh University Press.

Hassanzade, M., \& Narafshan, M. H. (2016). A Study on Input Quality and Second Language Grammar Achievement in Young Children. International Journal of English Language Teaching, 4, 70-82. https://doi.org/10.5296/ijele.v4i1.9006

Hoare, P., \& Kong, S. (2008). Late Immersion in Hong Kong: Still Stressed But Making Progress? In T. W. Fortune, \& D. J. Tedick (Eds.), Pathways to Multilingualism: Emerging Perspectives on Immersion Education (pp. 242-263). Clevedon: Multilingual Matters. https://doi.org/10.21832/9781847690371-015

Inagaki, S. (2001). Motion Verbs with Goal PPs in the L2 Acquisition of English and Japanese. Studies in Second Language Acquisition, 23, 153-170. 
https://doi.org/10.1017/S0272263101002029

Javid, C. Z., Farooq, U., \& Gulzar, M. A. (2012). Saudi English-Major Undergraduates and English Teachers' Perceptions Regarding Effective ELT in the KSA: A Comparative Study. European Journal of Scientific Research, 85, 55-70.

Krashen, S. (1985). The Input Hypothesis. London: Longman.

Krashen, S. D., \& Terrell, T. D. (1983). The Natural Approach: Language Acquisition in the Classroom. New York: Pergamon Press.

LaJevic, L. (2013). The Lost and Found Space of the Arts in Education. International Journal of Education through Art, 9, 41-54. https://doi.org/10.1386/eta.9.1.41_1

Lightbown, P. M., \& Spada, N. (2006). How Languages Are Learned (3rd ed.). Oxford: Oxford University Press.

Long, M. (2000). Focus on Form in Task-Based Language Teaching. In R. Lambert, \& E. Shohamy (Eds.), Language Policy and Pedagogy: Essays in Honor of A. Ronald Walton (Chapter 10, pp. 179-192). Philadelphia, PA: John Benjamins Publishing Company. https://doi.org/10.1075/z.96.11lon

Marcelino, M. (2018). Considerations on the Role of Input in 12 Acquisition: Elt and Bilingual Contexts. Revista Intercâmbio, 37, 76-97.

Moore, C. R., Koller, J. A., \& Arago, M. K. (1994). The Role of Art in Language Learning. Journal of the Imagination in Language Learning and Teaching, 2, 1-16.

Rodgers, D. (2011). The Automatization of Verbal Morphology in Instructed Second Language Acquisition. IRAL, 49, 295-319. https://doi.org/10.1515/iral.2011.016

Schwartz, B. D. (1993). On Explicit and Negative Data Effecting and Affecting Competence and Linguistic Behavior. Studies in Second Language Acquisition, 15, 147-163. https://doi.org/10.1017/S0272263100011931

Schwartz, B. D., \& Sprouse, R. (1996). L2 Cognitive States and the Full Transfer/Full Access Model. Second Language Research, 12, 40-72. https://doi.org/10.1177/026765839601200103

Schwartz, B. D., \& Sprouse, R. A. (2013) Generative Approaches and the Poverty of the Stimulus. In J. Herschensihn, \& M. Young-Scholten (Eds.), The Cambridge Handbook of Second Language Acquisition (pp. 137-158). Cambridge: Cambridge University Press. https://doi.org/10.1017/CBO9781139051729.010

Selinker, L. (1972). Interlanguage. IRAL, 10, 209-231. https://doi.org/10.1515/iral.1972.10.1-4.209

Sharwood Smith, M. (1986). Comprehension versus Acquisition: Two Ways of Processing Input. Applied Linguistics, 7, 239-256. https://doi.org/10.1093/applin/7.3.239

Shaw, B. (1999). Pygmalion. New York: Brentano, 1916; Bartleby.com.

Shaw, B. (2006). Arms and the Man. New York: Penguin Group.

Shier, H. J. (1990). Integrating the Arts in the Foreign/Second Language Curriculum: Fusing the Affective and the Cognitive. Foreign Language Annals, 23, 301-314. https://doi.org/10.1111/j.1944-9720.1990.tb00375.x

Slabakova, R. (2008). Meaning in the Second Language. Berlin: Mouton de Gruyter. https://doi.org/10.1515/9783110211511

Smith, M., \& Vanpatten, B. (2014). Instructed SLA as Parameter Setting: Evidence from Earliest-Stage Learners of Japanese as L2. In A. Benati, C. Laval, \& M. J. Arche (Eds.), The Grammar Dimension in Instructed Second Language Learning (pp. 127-146). London: Bloomsbery.

White, L. (1985). The Pro-Drop Parameter in Adult Second Language Acquisition. Lan- 
guage Learning, 35, 47-62. https://doi.org/10.1111/j.1467-1770.1985.tb01014.x

White, L. (1989). Universal Grammar and Second Language Acquisition. Amsterdam: John Benjamins. https://doi.org/10.1075/lald.1

White, L. (1990). Second Language Acquisition and Universal Grammar. Studies in Second Language Acquisition, 12, 121-133.

https://doi.org/10.1017/S0272263100009049

White, L. (2003). Second Language Acquisition and Universal Grammar. Cambridge: CUP. https://doi.org/10.1017/CBO9780511815065

Zhang, S. (2009). The Role of Input, Interaction and Output in the Development of Oral Fluency. English Language Teaching, 2, 91-100. https://doi.org/10.5539/elt.v2n4p91 